\title{
Progressive Ataxia and Neurologic Regression in RFXANK-Associated Bare Lymphocyte Syndrome
}

Essa Alharby, MSc,* Mona Obaid, MD, * Mohammed A.O. Elamin, MD, Makki Almuntashri, MD, Ismail Bakhsh, PhD, Manar Samman, PhD, Roy W.A. Peake, PhD, Ali Alasmari, MD, and Naif A.M. Almontashiri, PhD

Neurol Genet 2021;7:e586. doi:10.1212/NXG.0000000000000586

\section{Abstract}

\section{Objective}

To identify the genetic cause of a late-onset immunodeficiency and subacute progressive neurodegenerative disease affecting cognition, motor, visual, and cerebellar systems in a patient with a family history of 2 younger siblings with an early-onset immunodeficiency disease.

\section{Methods}

Physical examinations, immunologic, brain MRI, whole-exome sequencing, and segregation studies were used to identify the genetic and neuroimmunologic etiology of disease in this family.

\section{Results}

We identified a homozygous loss-of-function (LOF) mutation $(c .271+1 \mathrm{G}>\mathrm{C}$ ) in the RFXANK gene in the index patient and one of his younger affected siblings. Biallelic mutations in the RFXANK gene are known to cause bare lymphocyte syndrome (BLS) type II, complementation group $\mathrm{B}$. The clinical and immunologic investigations were consistent with a clinical diagnosis of BLS type II. MRI demonstrated global cerebral and cerebellar atrophy with white matter signal changes in the index case.

\section{Conclusions}

In addition to BLS type II, our study has expanded and further characterized the phenotype associated with the LOF of RFXANK to include progressive neurodegenerative disease. Our study also provides evidence for the impact of LOF on brain development and function. Thus, early bone marrow transplantation, as a standard of care for BLS, could prove to be protective against the neurologic phenotypes in this group of patients.

\author{
Correspondence \\ Dr. Almontashiri \\ nmontashri@taibahu.edu.sa
}




\section{Glossary}

WES = whole-exome sequencing; LOF = loss of function; BLS = bare lymphocyte syndrome; CIITA = class II transactivator; BMT = bone marrow transplantation; IVIG = IV immunoglobulin; GATK = genome analysis tool kit; CAP = College of American Pathologists; ACMG = American College of Medical Genetics; HSV = herpes simplex virus; RFXANK = regulatory factor X, ankyrin; CMV = cytomegalovirus; BMI = body mass index; MHC-II = major histocompatibility complex class II; RFX5 = regulatory factor 5; RFXAP = RFX-associated protein.

The bare lymphocyte syndrome (BLS) is a primary immunodeficiency syndrome caused by major histocompatibility complex class II (MHC-II) deficiency, resulting from biallelic inactivating mutations in genes encoding transacting transcription factors required for the expression of the major MHC class II molecules. ${ }^{1}$ This results in the generation of lymphocytes lacking MHC-II, hence the name, bare lymphocyte. MHC-II expression is regulated by 4 transacting factors: class II transactivator (CIITA), regulatory factor $\mathrm{X}$, ankyrin repeat-containing (RFXANK), regulatory factor 5 (RFX5), and RFX-associated protein (RFXAP). Mutations in all 4 regulatory genes are associated with different complementation groups of BLS. ${ }^{1}$

The RFXANK gene encodes a subunit of the tripartite RFX complex, required for regulating the transcription and assembly of the MHC-II genes and products. ${ }^{2}$ The RFXANK protein is expressed in many tissues including lymphocytes and brain (in particular basal ganglia, hippocampal, cerebral cortex, and cerebellum) (proteinatlas.org/ENSG00000064490-RFXANK/tissue). The RFXANK protein has a unique C-terminal domain containing an ankyrin repeats motif that is involved in proteinprotein interaction. ${ }^{2}$ The RFXANK protein provides the scaffold for the formation of the RFX complex containing RFXANK, RFX5, and RFXAP proteins and allows for RFX5 protein interaction with the motif boxes of MHC-II promoters. ${ }^{3}$

Mutations in the RFXANK gene are the common cause of BLS, group B. ${ }^{4}$ It is an autosomal recessive lethal primary combined immunodeficiency affecting both thymic epithelium and bone marrow-derived cells. ${ }^{5}$ Affected cells lack antigen-presenting surface receptors causing $\mathrm{CD} 4^{+}$lymphocyte populations to be incompletely developed with impaired $\mathrm{CD} 4^{+} \mathrm{T}$ cell-mediated immune response. In addition, the humoral immunity of $\mathrm{B}$ cells is severely impaired in these patients, resulting in the absence or reduction of IgG, IgM, and IgA. The clinical manifestations vary among patients; however, affected children show similar major clinical features of septicemia and multiple recurrent infections of the respiratory, gastrointestinal, and urinary tracts. Diffuse interstitial pneumonia is a common feature among patients with recurrent upper respiratory tract infections including sinusitis and otitis. In addition, many patients have failure to thrive, recurrent or protracted diarrhea, and malabsorption due to gastrointestinal tract infections. ${ }^{4,5}$ Of interest, 2 studies reported an additional phenotype of gait ataxia in 2 patients with BLS due to loss-offunction (LOF) mutations in RFXANK, ${ }^{6,7}$ However, aside from having ataxia, they did not provide any additional neurologic or imaging data to further describe and characterize the phenotype.
In the present study, we report a splice site mutation in the RFXANK gene (NM_003721.3:c.271+1G>C) in 2 Saudi siblings. Both patients have immunodeficiency, with the elder having a novel additional late-onset neurologic phenotype of progressive neurodegenerative disease.

\section{Methods}

\section{Standard Protocol Approvals, Registrations, and Patient Consents}

Whole-exome sequencing (WES) studies were indicated based on the phenotype and family history. Informed consent was obtained from all participants as per approved institutional review board (IRB) protocols (TU MLT-2019-07 and Ataxia IRB log \# 15-445) at Taibah University and King Fahad Medical City, respectively.

\section{Molecular Testing and Variants Curation}

WES was performed in a clinical and College of American Pathologists-accredited commercial laboratory as previously described. ${ }^{8}$ Briefly, DNA libraries for WES were prepared and sequenced using the SureSelect Kit (Agilent, Santa Clara, CA) and Hiseq2000 platform (Illumina, San Diego, CA), respectively. Variant calling was performed using the Genome Analysis Toolkit. The variant was classified and reported according to the American College of Medical Genetics guidelines. $^{9}$

\section{Data Availability}

The data that support the findings of this study are available from the corresponding author on request.

\section{Results}

\section{Clinical Data}

We present 2 siblings with different ages of BLS onset and additional neurologic presentations in the elder sibling.

\section{Case III: 3}

A 17-year-old boy (III: 3), presented with a history of recurrent otitis media for 8 months (figure 1). The otitis media was not responsive to antibiotics and was complicated by a ruptured tympanic membrane and continued discharges. The patient was asymptomatic before the onset of infection. After the infection, he initially developed worsening of gait and speech difficulties, followed by cognitive symptoms. His 


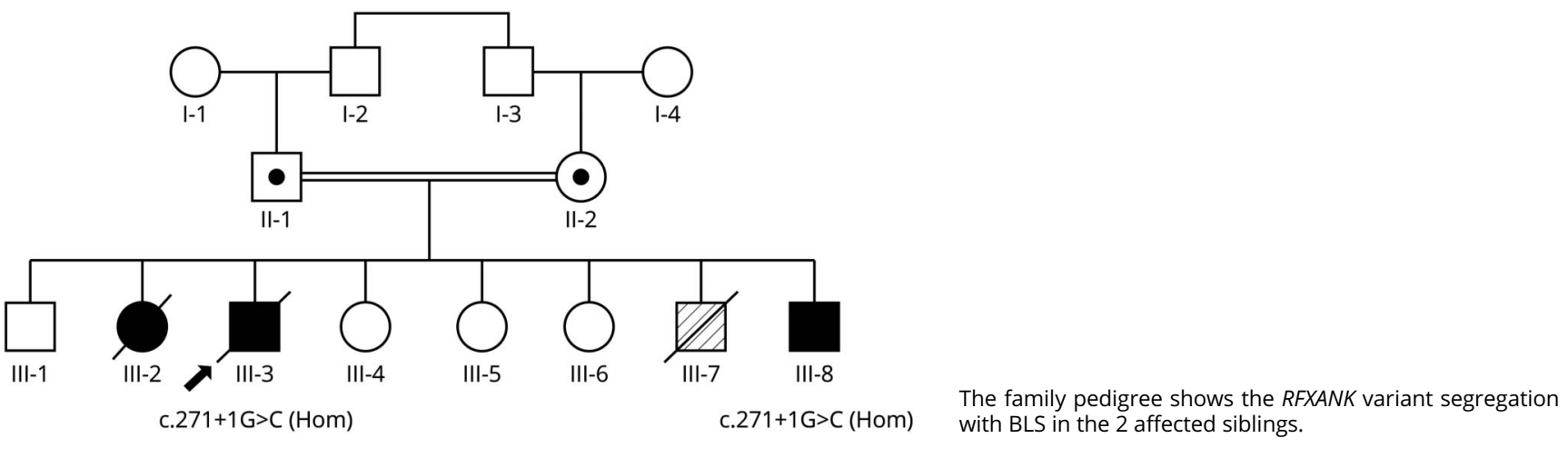

vision was the last to be affected. The neurologic complaint progressed, and the patient was unable to walk on admission to the hospital. The patient had no history of recurrent infections, aside from recurrent herpes simplex virus (HSV) infection before this admission. However, we cannot exclude that the patient had other infections during his childhood that did not manifest clinically, such as a previous cytomegalovirus infection, as indicated by his positive IgG and negative IgM testing (supplemental file and table e-1, links. lww.com/NXG/A407). The patient had no history of neurologic, visual, or cognitive complaints before his presentation. The neurologic examination was only performed on arrival at our center.

The patient was a product of a consanguineous marriage (first degree), with normal pregnancy and delivery. As per his

Figure 2 MRI Findings in the Index Case (III: 3)
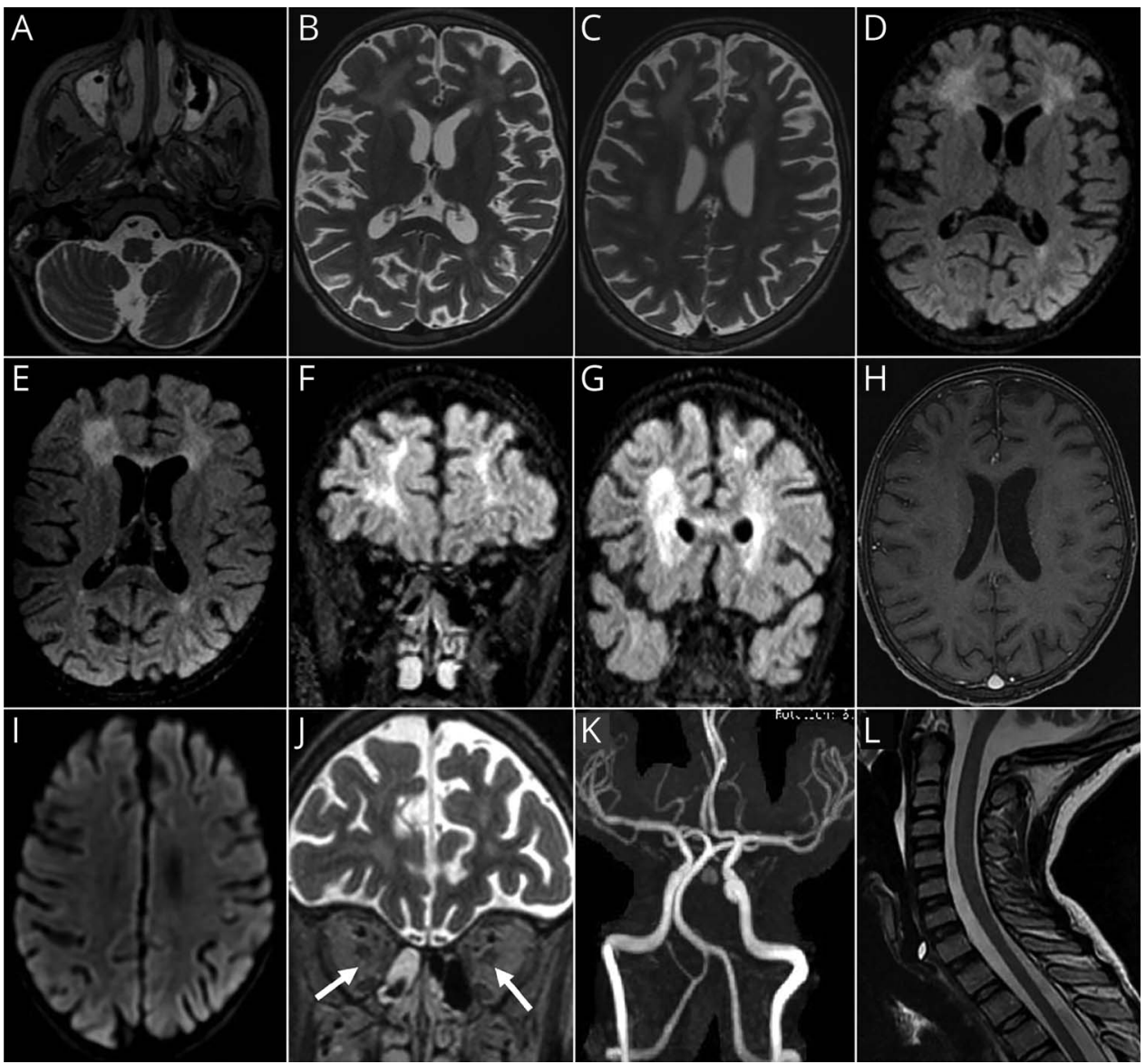

Axial T2-weighted images (A-C), axial T2 fluid-attenuated inversion recovery (FLAIR) (D-E), coronal T2 FLAIR $(\mathrm{F}-\mathrm{G})$, axial T1 postcontrast $(\mathrm{H})$, diffusion-weighted image (I), coronal T2WI (T2-weighted image) (J), 3D-TOF circle of Willis $(\mathrm{K})$, and sagittal T2WI of the spinal cord (L) showed diffuse atrophy of both cerebral hemispheres and mild cerebellar atrophy. There was bilateral, asymmetrical white matter hyperintense signal abnormality involving frontal, parietal, and temporal lobes on T2WI and FLAIR with no diffusion restriction or postcontrast enhancement (A-I). There was atrophy of optic nerves $(J$, arrows) and features of recurrent ear infections and sinusitis (A). The main intracranial arteries and spinal cord were unremarkable, respectively $(\mathrm{K}$ and $\mathrm{L}$ ). 
Table Immunologic and CSF Investigations for the Affected Siblings With BLS

\begin{tabular}{|c|c|c|c|c|}
\hline Immunophenotyping & III: 8 & III: 3 (P1) & III: 3 (P2) & Reference range \\
\hline Lymphocytes (cells/ $\mu \mathrm{L}$ ) & 1.04 & 1.53 & 1.8 & $214-685$ \\
\hline CD19 (cells/ $/ \mu \mathrm{L})$ & 0.16 & 0.03 & 0.05 & $0.70-1.60$ \\
\hline CD19 (\%) & 59 & 2.3 & 3 & $4-23$ \\
\hline CD19/DR+ (cells/ $\mu \mathrm{L})$ & 0 & 0 & 0 & $0.7-1.6$ \\
\hline CD19/DR+ (\%) & 0 & 0 & 0 & 100 \\
\hline CD3 (cells/ $\mu \mathrm{L}$ ) & 0.28 & 1.43 & 1.65 & $2.20-4.10$ \\
\hline CD3 (\%) & 27.0 & 93 & 91 & $61-70$ \\
\hline CD4 (cells/ $\mu \mathrm{L}$ ) & 0.06 & 0.17 & 0.12 & $1.40-2.80$ \\
\hline CD4 (\%) & 6.3 & 11.7 & 7 & $36-44$ \\
\hline CD8 (cells/ $\mu \mathrm{L}$ ) & ND & 1.03 & 1.23 & $0.80-1.80$ \\
\hline CD8 (\%) & 90 & 68 & 69 & $20-30$ \\
\hline CD4/CD8 ratio & 0.3 & 0.2 & 0.1 & $1.0-5.0$ \\
\hline Activated T cells (cells/ $\mu \mathrm{L}$ ) & 0 & 0 & 0 & $0-14$ \\
\hline Activated T cells (\%) & 0 & 0 & 0 & \\
\hline NK cells (cells/ $\mu \mathrm{L}$ ) & 0.13 & 0.05 & 0.11 & $0.20-0.60$ \\
\hline NK cells $(\%)$ & 12 & 3.8 & 6 & $5.0-10.0$ \\
\hline \multicolumn{5}{|l|}{ ANCA } \\
\hline MPO & ND & 0.9 & 0.7 & $0-20.0$ \\
\hline PR3 & ND & 1.4 & 2.1 & $0-20.0$ \\
\hline \multicolumn{5}{|l|}{ ANA } \\
\hline Screening & ND & 0.5 & 0.5 & $>1.5$ is positive \\
\hline IFA & ND & Negative & Negative & \\
\hline $\operatorname{lgG}(g / L)$ & 3.6 & 6.43 & 5.77 & $7.00-16.00$ \\
\hline $\operatorname{lgM}(g / L)$ & 0.2 & 0.47 & 0.42 & $0.40-2.30$ \\
\hline $\operatorname{lgA}(\mathrm{g} / \mathrm{L})$ & 0.2 & $<0.26$ & $<0.26$ & $0.70-4.00$ \\
\hline C3 (g/L) & ND & 0.87 & ND & $0.90-1.80$ \\
\hline $\mathrm{C} 4(\mathrm{~g} / \mathrm{L})$ & ND & 0.23 & ND & $0.10-0.40$ \\
\hline \multicolumn{5}{|l|}{ CSF studies } \\
\hline Protein (g/L) & $0.08(0.15-0.45)$ & $44.7(60-80)$ & ND & \\
\hline Glucose (mmol/L) & $3.6(2.2-3.9)$ & $4.7(3.9-7.7)$ & ND & \\
\hline \multicolumn{5}{|l|}{ Hematology } \\
\hline RBC & 0 & 0 & ND & $0-5$ \\
\hline WBC & 0 & 1 & ND & $0-5$ \\
\hline C/S & No growth & No growth & & \\
\hline Cryptococcal infection & ND & No growth & ND & \\
\hline Genus Brucella-PCR & ND & Negative & ND & \\
\hline HSV 1 and 2-PCR & ND & Negative & ND & \\
\hline
\end{tabular}

Abbreviations: $\mathrm{ANA}=$ antinuclear antibody; $\mathrm{ANCA}=$ antineutrophil cytoplasmic antibody; $\mathrm{C} / \mathrm{S}=$ culture and sensitivity; $\mathrm{C} 3=$ complement $\mathrm{C} 3 ; \mathrm{C} 4=\mathrm{complement}$ $\mathrm{C} 4 ; \mathrm{HSV}=$ herpes simplex virus; IFA = indirect immunofluorescence; $\mathrm{MPO}=$ myeloperoxidase; $\mathrm{ND}=$ not done; $\mathrm{NK}=$ natural killer; $\mathrm{P} 1$ = first time point; $\mathrm{P} 2$ = second time point (1 month apart from P1); PR3 = proteinase 3; RBC = red blood cell; WBC = white blood cell. 
parents, he had normal motor milestones and completed his intermediate school education with no concerns regarding his cognition, speech, behavior, social development, and interaction. However, a formal assessment was not available. The patient's medical history was significant for recurrent HSV infections of the skin at age 11, 14, and 17 years. During the 8-month course of the otitis media, the patient developed neurologic symptoms. The gait, speech, and cognition only worsened after the sequence of recurrent ear infections.

On clinical assessment, height, weight, and BMI were $139 \mathrm{~cm}, 19$ $\mathrm{kg}$, and $9.8 \mathrm{~kg} / \mathrm{m}^{2}$, respectively. He had no dysmorphic or syndromic features. He had an intact comprehension with severe dysarthria. On ophthalmologic examination, he had an impaired pursuit with left gaze preference and no gaze palsy. Pupils were bilaterally symmetrical and nonreactive. The sclera, cornea, and lens were normal, with no abnormal scleral vessels. Fundoscopy showed normal retina and retinal vessels with bilateral pallor of optic disc. He had severe bilateral sensorineural hearing loss (left $>$ right). He had truncal ataxia, generalized spasticity, with motor power of 2/4 in upper and lower extremities (using the Medical Research Council's scale of muscle power [Memorandum No. 45]), and mild contractures in the elbows and knees. He had brisk reflexes with bilateral up-going toes. He was able to sit with assistance but unable to stand. He had silver scaly lesions over his abdomen and flanks that were later confirmed to be psoriatic dermatitis by skin biopsy.

The serologic workup pursued during his first admission is detailed in table e-1 (links.lww.com/NXG/A407). Investigations performed included a normal echocardiogram and Holter monitor test. The EEG study during awake state was abnormal due to the presence of diffuse moderate to high voltage rhythmic sharp and slow waves with no maximum intensity and no electrographic seizures. Brain MRI performed at age 17 years revealed moderate global cerebral volume loss with asymmetrical bilateral subcortical to periventricular white matter patchy nonenhancing T2 hyperintense signal abnormality affecting the frontal, parietal, and temporal lobes. Infratentorially, the cerebellum was involved to a lesser extent with mild diffuse volume loss and small nonenhancing focus of $\mathrm{T} 2$ hyperintense signal abnormality in the dentate nuclei (figure 2, A-I). The MRI changes were consistent with the clinical course. In addition, MRI demonstrated bilateral optic nerve atrophy (figure 2J) and secretions in the paranasal sinuses with fluid accumulation in the ears and mastoid air cells related to recurrent infections with sinusitis and otomastoiditis (figure 2A). The brainstem and spinal cord were spared, and the main intracranial arteries were unremarkable (figure $2 \mathrm{~K}$ and $\mathrm{L}$ ).

Hospital course: the patient's poor neurologic status worsened, even with the use of appropriate antibiotic treatment for the ongoing infections (otitis media, followed by aspiration pneumonia). He developed generalized seizures and was treated accordingly. He was discharged to a local community hospital to continue the course of antibiotics. In the local hospital, he developed recurrent infections and bedsores. In addition, he developed dysphagia necessitating the insertion of a percutaneous endoscopic gastrostomy tube. The patient lost to follow-up at our center due to his poor general medical condition and risk of transfer.

A year later, at age 18 years, the patient was readmitted to our center with severe malnutrition, worsening neurologic condition, and aspiration pneumonia. The second hospital course was complicated by recurrent infection (aspiration pneumonia, hospital acquired pneumonia, and infected bed ulcers). Neurologically, the patient had exhibited a significant decline from the 1st admission, with progressive loss of cognitive and motor function. He was mute and had only light perception in vision, with motor response only to pain. He had generalized contracture and a deep sacral bedsore. Overall, the neurologic decline was happening in a stepwise manner with every infection. Before death, he had no visual, verbal, or motor response to any stimuli. He died due to respiratory failure.

\section{Laboratory Investigations}

Chemical, serologic, microbiological, hematologic, and additional investigations on blood, sputum, stool, and urine samples collected during the 1st and 2nd admissions were largely unremarkable (details in supplemental file and table e-1, links.lww.com/NXG/A407). CSF studies during the 2nd admission did not show evidence of CNS infection (table). However, the immunologic workup (2 time points) was consistent with BLS as he had a persistent panhypogammaglobulinemia and low CD4 resulting in a decreased CD4/CD8 ratio (table). MHC-II human leukocyte antigen-DR isotype (HLA-DR) was not expressed on monocytes and $\mathrm{B}$ cells, leading to the absence of activated $\mathrm{T}$ cells, which is a hallmark of BLS. Therefore, he was kept on IV immunoglobulin (IVIG) infusion (every 4 weeks), bilevel positive airway pressure for type 2 respiratory failure, and antibiotics for infections.

\section{Case III: 8}

The 6-year-old male sibling (III: 8 ) was a product of full term pregnancy with birth weight of $4 \mathrm{~kg}$ and no neonatal intensive care unit admission (figure 1). At age 2 years, he was referred to our center with chronic diarrhea, failure to thrive, recurrent chest infections, and oral thrush for 1 year. On examination, his weight was $6.1 \mathrm{~kg}(<3 \mathrm{rd}$ centile) and height was $78 \mathrm{~cm}$ ( $<3$ rd percentile). He was normocephalic, nondysmorphic, and severely wasted, with oral thrush and chest pectus excavatum. The abdomen was distended with no organomegaly. His neurologic examination and development were normal. CSF studies during his admission were unremarkable and did not show evidence for a CNS infection (table). However, brain MRI was not pursued because he had no neurologic phenotype, and therefore, his parents rejected further testing.

The immunologic workup was consistent with BLS (table). He was commenced on total parenteral nutrition, received IVIG, and referred to an outside center where he had 
successful bone marrow transplantation (BMT). He is currently 8 years old and meeting his motor and cognitive developmental milestones.

\section{Other Siblings}

There were 2 additional siblings: a sister (III: 2) who died at age 1.5 years with pneumonia and clinical suspicion of immunodeficiency and a brother (III: 7) who died at age 1 month with congenital heart disease (figure 1). However, neither had genetic testing, MRI, or other investigations including immunodeficiency laboratory workup.

\section{Molecular Testing and Interpretation}

Based on the family history and clinical manifestations, WES was ordered to investigate the genetic etiology of their conditions. WES revealed a homozygous pathogenic variant (NM 003721.3:c.271+1G>C) in the RFXANK gene in the affected siblings with BLS (III: 3 and III: 8). The molecular results confirmed the immunologic and clinical diagnosis of BLS. However, aside from this homozygous LOF variant in RFXANK, no additional variants were detected in neurologically relevant, known, or candidate genes. The parents were heterozygous carriers.

\section{Discussion}

In this study, we report 2 siblings with a genetic diagnosis of BLS due to a LOF variant in RFXANK. The older sibling (III: 3 ) had a later age at onset (17 years). His immunodeficiency was only apparent after a series of recurrent infections, with an additional progressive neurodegenerative disease affecting cognitive, motor, visual, and cerebellar systems, leading to death despite receiving appropriate antibiotics, IVIG therapy, and nutritional support. This neurologic phenotype correlated with the MRI findings of global cerebral and cerebellar atrophy and white matter signal changes. Our study expands and links this neurological phenotype to BLS type II.

Patients with BLS have MHC-II deficiency due to biallelic inactivating mutations in genes, such as RFXANK (BLS; group B). BLS group B is typically diagnosed in the first year of life (mean age at presentation is $4.2-10$ months) as a result of persistent respiratory, gastrointestinal, and urinary tract infections. However, there is variable expressivity and clinical heterogeneity associated with the reported pathogenic variants in RFXANK. ${ }^{6,7}$ Rare clinical features such as facial dysmorphism, oral HPV, candidiasis, and genitourinary infections are reported in some patients with biallelic inactivation of RFXANK. An additional phenotype of infantileonset ataxia was reported in 2 patients with and without dysarthria, who both died without receiving BMT and were subsequently found to have biallelic LOF mutations in RFXANK. ${ }^{6,7}$ However, there was a lack of clinical and radiologic characterization of the ataxia in these patients. Of interest, our elder patient had a late-onset BLS and neuroregression. Of note, adult-onset BLS due to mutations in genes including RFXANK has been reported without a clear mechanism, explaining the variability and age-dependent penetrance of the immunologic phenotype. ${ }^{5,10,11}$ Of interest, all 3 patients (including the current patient) with ataxia were homozygous for LOF variants in RFXANK. Moreover, the neurologic phenotypes in these patients coincided with the onset of BLS, whether early or late onset, suggesting that it was caused by the same mechanism and possibly an immunologic trigger. The additional and rare features could lead to delay in diagnosis and timely intervention. Therefore, additional reports and cohorts are needed to establish the phenotypic spectrum and variability associated with BLS group B.

The pathologic and biological mechanisms by which RFXANK deficiency can explain the neurologic phenotypes are unclear. However, RFXANK is abundantly expressed in brain tissues including basal ganglia, hippocampal, cerebral cortex, and cerebellum. Of interest, MHC-II is expressed in the human neural progenitors and neurons independently of inflammatory stimuli, supporting a nonimmune role of MHC-II in the early development of the brain. ${ }^{12}$ Therefore, it is possible that RFXANK is directly or indirectly (through MHC-II) required for brain development and maintaining its functions and structure. The clinical status of this patient has rapidly worsened from normal to bed bound in 8 months and then progressed in a few months to loss of vision, hearing, and response to surroundings. During this rapid course, he was rarely off antibiotics and had ongoing bacterial infections (lung, urine, and skin [pressure sores]). It seems that the bacterial (and not the viral) infection was possibly the trigger for different immunologic responses or pathways that led to the neurologic regression. These hypotheses have yet to be tested to examine the developmental and functional impact of RFXANK deficiency on the developing neurons and brain function under different immunologic conditions.

Despite having the same RFXANK variant as his elder sibling, the younger sibling (III: 8) had an early-onset form of BLS without any neurologic phenotype until his current age 8 years. This variability in the age of onset between the two siblings along with the lack of the neurological phenotype in the younger sibling may be explained by (1) variable expressivity due to gene modifiers, (2) an age-dependent penetrance of the neurologic phenotype necessitating periodical neurologic evaluations and imaging studies, or (3) a rescue and protective effect of BMT as result of the reconstitution of the immune system and the expression of RFXANK from the new bone marrow cells; reminiscent of the protective effect of the hematopoietic stem cell transplantation on the neurocognitive outcomes in mucopolysaccharidosis type I, for example. $^{13}$ It is possible that the neurologic phenotype is underrepresented and ultra-rare in this group of patients with BLS because they are either protected, as a result of the early $\mathrm{BMT}$, or die before onset of the neurologic symptoms. The neurologic follow-up of the younger sibling who received BMT and was free of any neurologic phenotype, along with other similar studies, would provide clinically useful data to test this hypothesis. 
In conclusion, this study provides a neurologic phenotypic expansion of the RFXANK-associated BLS. The potential dual functions of RFXANK in the immune system and the CNS warrant further follow-up studies. The possible dual functions of RFXANK can be therapeutically impactful in protecting patients with BLS from the neurologic phenotype by rescuing RFXANK deficiency through donor BMT or ex vivo gene edited or expressed RFXANK in an autologous BMT setting.

\section{Disclosure}

The authors report no disclosures relevant to the manuscript. Go to Neurology.org/NG for full disclosures.

\section{Acknowledgment}

The authors thank the family for agreeing to participate in this study.

\section{Study Funding}

Deputyship for Research \& Innovation, Ministry of Education in Saudi Arabia, project number 821.

\section{Publication History}

Received by Neurology: Genetics December 8, 2020. Accepted in final form February 17, 2021.

\section{Appendix Authors}

\begin{tabular}{lll}
\hline Name & Location & Contribution \\
\hline $\begin{array}{l}\text { Essa Alharby, } \\
\text { MSc }\end{array}$ & $\begin{array}{l}\text { Taibah University, Medina, } \\
\text { Saudi Arabia }\end{array}$ & $\begin{array}{l}\text { Data analysis and drafted } \\
\text { the manuscript }\end{array}$ \\
\hline $\begin{array}{l}\text { Mona Obaid, } \\
\text { MD }\end{array}$ & $\begin{array}{l}\text { King Fahad Medical City, } \\
\text { Riyadh, Saudi Arabia }\end{array}$ & $\begin{array}{l}\text { Neurologic evaluation } \\
\text { and reviewed the } \\
\text { manuscript }\end{array}$ \\
\hline $\begin{array}{l}\text { Mohammed } \\
\text { A.O. Elamin, }\end{array}$ & King Fahad Medical City, & $\begin{array}{l}\text { Clinical genetic } \\
\text { Riyadh, Saudi Arabia } \\
\text { MD }\end{array}$ \\
\hline
\end{tabular}

\section{References}

1. Reith W, Mach B. The bare lymphocyte syndrome and the regulation of MHC expression. Annu RevImmunol 2001;19:331-373.

2. Nekrep N, Geyer M, Jabrane-Ferrat N, Peterlin BM. Analysis of ankyrin repeats reveals how a single point mutation in RFXANK results in bare lymphocyte syndrome. Mol Cell Biol 2001;21:5566-5576.

3. Nekrep N, Jabrane-Ferrat N, Peterlin BM. Mutations in the bare lymphocyte syndrome define critical steps in the assembly of the regulatory factor $\mathrm{X}$ complex. Mol Cell Biol 2000;20:4455-4461.

\section{Appendix (continued)}

\begin{tabular}{|c|c|c|}
\hline Name & Location & Contribution \\
\hline $\begin{array}{l}\text { Makki } \\
\text { Almuntashri, } \\
\text { MD }\end{array}$ & $\begin{array}{l}\text { King Saud bin Abdulaziz } \\
\text { University for Health } \\
\text { Sciences, Riyadh, Saudi } \\
\text { Arabia }\end{array}$ & $\begin{array}{l}\text { Neuroradiologic } \\
\text { evaluation and reviewed } \\
\text { the manuscript }\end{array}$ \\
\hline $\begin{array}{l}\text { Ismail } \\
\text { Bakhsh, PhD }\end{array}$ & $\begin{array}{l}\text { King Fahad Medical City, } \\
\text { Riyadh, Saudi Arabia }\end{array}$ & $\begin{array}{l}\text { Immunologic data } \\
\text { acquisition and } \\
\text { interpretation }\end{array}$ \\
\hline $\begin{array}{l}\text { Manar } \\
\text { Samman, PhD }\end{array}$ & $\begin{array}{l}\text { King Fahad Medical City, } \\
\text { Riyadh, Saudi Arabia }\end{array}$ & $\begin{array}{l}\text { Molecular data } \\
\text { acquisition and } \\
\text { interpretation }\end{array}$ \\
\hline $\begin{array}{l}\text { Roy W.A. } \\
\text { Peake, PhD }\end{array}$ & $\begin{array}{l}\text { Boston Children's } \\
\text { Hospital, Boston, USA }\end{array}$ & $\begin{array}{l}\text { Biochemical data } \\
\text { interpretation and } \\
\text { reviewed the manuscript }\end{array}$ \\
\hline $\begin{array}{l}\text { Ali Alasmari, } \\
\text { MD }\end{array}$ & $\begin{array}{l}\text { King Fahad Medical City, } \\
\text { Riyadh, Saudi Arabia }\end{array}$ & $\begin{array}{l}\text { Clinical genetic } \\
\text { evaluation and reviewed } \\
\text { the manuscript }\end{array}$ \\
\hline $\begin{array}{l}\text { Naif A.M. } \\
\text { Almontashiri, } \\
\text { PhD }\end{array}$ & $\begin{array}{l}\text { Taibah University, Medina, } \\
\text { Saudi Arabia }\end{array}$ & $\begin{array}{l}\text { Funded the project, } \\
\text { supervised and managed } \\
\text { the study, interpreted the } \\
\text { data, and drafted the } \\
\text { manuscript }\end{array}$ \\
\hline
\end{tabular}

4. Wiszniewski W, Fondaneche MC, Louise-Plence P, et al. Novel mutations in the RFXANK gene: RFX complex containing in-vitro-generated RFXANK mutant binds the promoter without transactivating MHC II. Immunogenetics 2003;54:747-755.

5. Ouederni M, Vincent QB, Frange P, et al. Major histocompatibility complex class II expression deficiency caused by a RFXANK founder mutation: a survey of 35 patients. Blood 2011;118:5108-5118.

6. Ben-Mustapha I, Ben-Farhat K, Guirat-Dhouib N, et al. Clinical, immunological and genetic findings of a large Tunisian series of major histocompatibility complex class II deficiency patients. J Clin Immunol 2013;33:865-870.

7. Farrokhi S, Shabani M, Aryan Z, et al. MHC class II deficiency: report of a novel mutation and special review. Allergol Immunopathol (Madr) 2018;46:263-275.

8. Alhebbi H, Peer-Zada AA, Al-Hussaini AA, et al. New paradigms of USP53 disease: normal GGT cholestasis, BRIC, cholangiopathy, and responsiveness to rifampicin. J Hum Genet 2021;66:151-159.

9. Richards S, Aziz N, Bale S, et al. Standards and guidelines for the interpretation of sequence variants: a joint consensus recommendation of the American college of medical genetics and genomics and the association for molecular pathology. Genet Med 2015; 17:405-424.

10. Djidjik R, Messaoudani N, Tahiat A, et al. Clinical, immunological and genetic features in eleven Algerian patients with major histocompatibility complex class II expression deficiency. Allergy Asthma Clin Immunol 2012;8:14.

11. Quan V, Towey M, Sacks S, Kelly AP. Absence of MHC class II gene expression in a patient with a single amino acid substitution in the class II transactivator protein CIITA. Immunogenetics 1999;49:957-963.

12. Vagaska B, New SEP, Alvarez-Gonzalez C, et al. MHC-class-II are expressed in a subpopulation of human neural stem cells in vitro in an IFNî 3-independent fashion and during development. Sci Rep 2016;6:24251.

13. Wang RY, Bodamer OA, Watson MS, Wilcox WR. Lysosomal storage diseases: diagnostic confirmation and management of presymptomatic individuals. Genet Med 2011;13:457-484. 


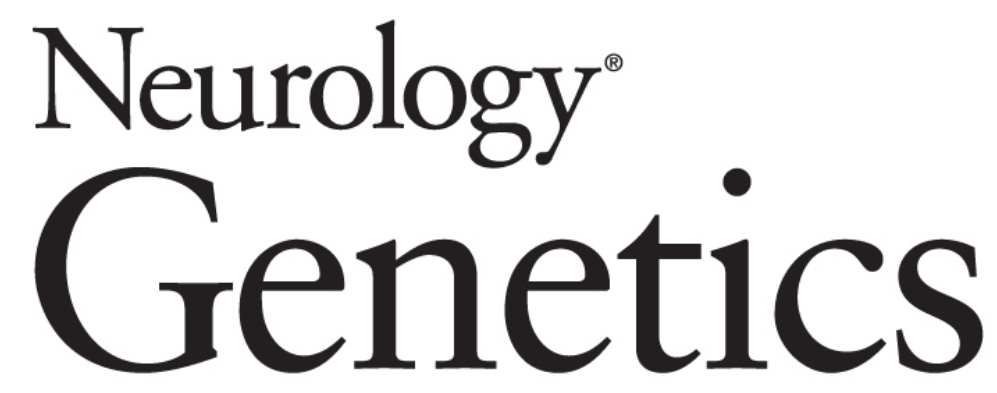

Progressive Ataxia and Neurologic Regression in RFXANK-Associated Bare Lymphocyte Syndrome

Essa Alharby, Mona Obaid, Mohammed A.O. Elamin, et al. Neurol Genet 2021;7;

DOI 10.1212/NXG.0000000000000586

This information is current as of April 9, 2021

Neurol Genet is an official journal of the American Academy of Neurology. Published since April 2015, it is an open-access, online-only, continuous publication journal. Copyright Copyright ( 2021 The Author(s). Published by Wolters Kluwer Health, Inc. on behalf of the American Academy of Neurology.. All rights reserved. Online ISSN: 2376-7839.

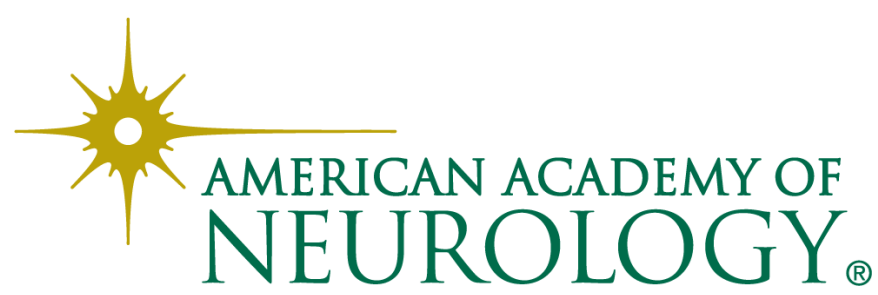




\section{Updated Information \& Services}

References

Subspecialty Collections

Permissions \& Licensing

\section{Reprints}

including high resolution figures, can be found at: http://ng.neurology.org/content/7/3/e586.full.html

This article cites 13 articles, 3 of which you can access for free at: http://ng.neurology.org/content/7/3/e586.full.html\#\#ref-list-1

This article, along with others on similar topics, appears in the following collection(s):

\section{All Genetics}

http://ng.neurology.org//cgi/collection/all_genetics

\section{Gait disorders/ataxia}

http://ng.neurology.org//cgi/collection/gait_disorders_ataxia

\section{MRI}

http://ng.neurology.org//cgi/collection/mri

Optic nerve

http://ng.neurology.org//cgi/collection/optic_nerve

Spinocerebellar ataxia

http://ng.neurology.org//cgi/collection/spinocerebellar_ataxia

Information about reproducing this article in parts (figures,tables) or in its entirety can be found online at:

http://ng.neurology.org/misc/about.xhtml\#permissions

Information about ordering reprints can be found online:

http://ng.neurology.org/misc/addir.xhtml\#reprintsus

Neurol Genet is an official journal of the American Academy of Neurology. Published since April 2015, it is an open-access, online-only, continuous publication journal. Copyright Copyright $\odot 2021$ The Author(s). Published by Wolters Kluwer Health, Inc. on behalf of the American Academy of Neurology.. All rights reserved. Online ISSN: 2376-7839.

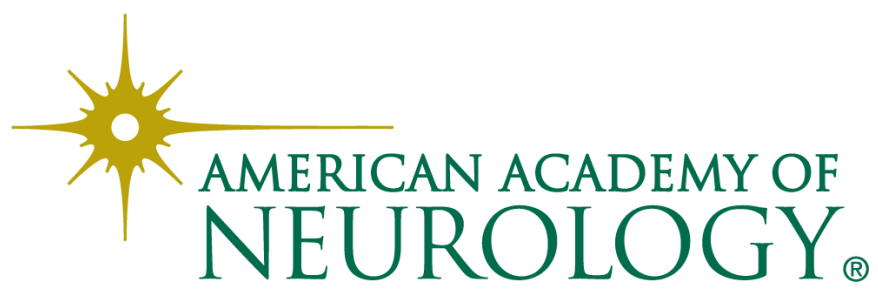

